\title{
Contradictions in climate concern: performances of home and away
}

Scott A. Cohen

Bournemouth University

James E.S. Higham

University of Otago

\section{Introduction}

There is a burgeoning body of academic literature (e.g. Becken, 2007; Gössling et al, 2006; Hares et al, 2010) that examines if and how consumer concern about climate change manifests itself in tourist behavioural practices. These works build on a wealth of previous studies that consider how consumer concern over issues of sustainable development may also affect tourist behaviour. Indeed, whilst tourism's climate impacts have lately been a hot topic, there is no doubt that issues of climate change are within the remit of, and need to be considered alongside, wider discourses of sustainable development (Weaver, 2011).

Recent research focussed explicitly on the climate impacts of tourism and associated tourism transport reflects the realisation in the academy that the tourism industry, characterised by energy-intensive consumption, is a significant contributor to accelerating global climate change. Despite the claim, however, that tourism is increasingly blended into the fabric of everyday life (Edensor, 2007), the mass of tourism still largely occurs as a bounded experience outside the rhythms of the day-to-day, which is both extraordinary and often involving conspicuous consumption. With tourism often experienced as an event set apart from the day-to-day, it is unsurprising that few studies, with the notable exception of Barr et al (2010), have sought to understand tourist environmental concern in relation to a wider scope of everyday lives and daily decision-making.

The present chapter seeks to further understandings of how tourism consumption, and its consequent carbon emissions, are made sense of and justified by consumers in relation to everyday life decisions. Based on 30 open-ended, semi-structured interviews carried out in the United Kingdom and Norway in 2009, the chapter illustrates consistencies and 
inconsistencies in the climate sensitivities of UK and Norwegian consumers in relation to both everyday domestic (home) and tourism (away) practices. Modern theory on tourism as liminoid space (Turner, 1982) and postmodern theory that suggests personal identity (and consequently behaviour) is inconsistent and performed differently across varying contexts (Bell, 2008; Edensor, 2001) are used as complementary explanatory devices for understanding some of the participants' seemingly contradictory consumption decisions. The research consequently reveals significant paradoxes in consumer climate sensitivities between the everyday and holidays. These findings hold important implications for the viability of climate change mitigation strategies and sustainable development goals that rely, at least in part, on nudging individual lifestyles towards less carbon-intensive consumption choices.

\section{Consumer climate concern and tourism}

There is increasing pressure on the tourism industry to move to a sustainable emissions path (Gössling, 2009). It is widely acknowledged that the tourism industry is implicated in climate change in terms of both cause and effect. Tourism is an energy intensive industry (Becken, 2007 ) that is currently directly accountable for $4.4 \%$ of global $\mathrm{CO}_{2}$ emissions (Peeters \& Dubois, 2010). Of this amount, $40 \%$ can be conservatively attributed to tourist air travel (Gössling, 2009). In comparison with tourism transport alternatives such as rail, road and seabased passenger modes, air travel is the most harmful for the climate system (Gössling \& Peeters, 2007) and presents one of the tourism industry's largest challenges if it seeks to sustain contemporary aeromobility-dependent tourism practices (Burns \& Bibbings, 2009).

Correspondingly, much of the recent academic concern over tourism's climate change impacts has centred upon issues surrounding tourist air travel (Gössling \& Upham, 2009). Scholarship has engaged with a range of issues in this area, including, amongst others, the effectiveness of voluntary carbon offsets for aviation-based emissions (Smith \& Rodger, 2009), land-based alternatives to air travel that may qualify as modes of 'slow travel' (Dickinson et al, 2011), the multifarious ways in which tourist air travel is embedded within contemporary social life (Randles \& Mander, 2009a), the notion of excessive tourist air travel, or 'binge flying', as a site of behavioural addiction (Cohen et al, 2011) and consumer climate concern towards extreme long-haul air travel (Higham \& Cohen, 2011). Literature that focuses on consumer sensitivities towards tourism's climate change impacts, as manifest 
in modifications in attitudes and behaviours towards and within tourism practices, notes that 'such changes may include choice of destination and timing of visits, perhaps extending to the abandonment of some destinations, and the discontinuation of some forms of tourism' (de Freitas, 2005; Higham \& Cohen, 2011, p99). Whether these latter changes will actually materialize is still largely an open empirical question.

Consumer attitudes towards, and perceptions of, tourism's climate change impacts are both more widely explored than behavioural adaptations, and are to date a source of conflicting evidence. For instance, whereas Miller et al (2010) find public reluctance in the UK to engage in sustainable tourism through taking fewer holidays, Cohen and Higham (2011) report a growing movement of UK consumers who are approaching tourism-related air travel decisions with a 'carbon conscience'. Furthermore, whilst Gössling et al (2008, p875) observe that 'pro-environmental concerns are clearly emerging among consumers, and may play a significant role in travel decisions in the future', Hares et al (2010) note, at least for UK consumers, a lack of consideration of climate change in decision-making when planning holidays. Reinforcing this latter finding, Caletrío (2011) suggests that few UK tourists are willing to sacrifice aspects of their annual holidays based on environmental grounds.

Explanations for these contradictions in consumer climate concern in recent literature can be abstracted in a number of ways. First, seemingly conflictive findings in Caletrío (2011) and Cohen and Higham (2011) arguably represent voices from different cross-sections within UK society, with the former reflecting individuals who self-profess being financially constrained to a one-week annual holiday and the latter (upon whom the present chapter is also based) being comprised of relatively affluent, highly educated (and consequently hypermobile) individuals. Hence, individuals may express a higher willingness to sacrifice holidays when in the relatively privileged economic position of being able to afford multiple holidays per year. This highlights a need for future empirical research that analyses consumer concern over tourism's climate change impacts in relation to demographic variables such as income and education level. Second, pro-environmental attitudes offered by consumers can represent a filtered reluctance to present socially undesirable accounts of continued hyperconsumption in the face of accelerating climate change (Cohen et al, 2011). Lastly, there may be a dissonance between self-professed environmental attitudes and subsequent steps to modify behaviours. In particular, and most important for the aim of the present 
chapter, is the possibility of a tension between the contexts of everyday domestic life decisions and consumption choices made whilst away on holiday.

\section{Liminoid space and contextualised performances}

Tourism practices, for most individuals, exist in contexts largely set apart from everyday life. Both a modern perspective that positions tourism experiences as an escape from the everyday self (Cohen and Taylor, 1992; Cohen, 2010a), and a postmodern perspective that views selves, and in turn behaviours, as performed and contextually dependent (Bell, 2008), suggest that just because individuals perform one way in a situation, does not mean that behaviours transfer consistently across contexts. This has implications for understanding the transferability of pro-environmental attitudes and behaviours across differing life contexts, as each of these worldviews suggest that behaviour is contextually, or situationally, dependent.

Within modern literature on tourist motivation, the need to escape has long been posited as a key motivator for why some individuals go on holiday (Crompton, 1979; Dann, 1977). Crompton (1979, p416) notes the desire to 'escape from a perceived mundane environment', or in other words, the tedium of routine, forms one of the major motives driving tourist behaviour. Breaking from everyday routine is linked to Turner's (1982) description of the 'liminoid', characterised as a departure from the structure of everyday life (Lett, 1983). Sharpley (2003, p5-21) applies the liminoid to tourism experiences, noting that whilst away on holiday, tourists may feel 'temporarily freed from...household chores, social commitments and, generally, the behavioural norms and values of their society.' Furthermore, Kim and Jamal (2007, p.184) suggest that within 'liminal touristic space, conventional social norms and regulations are often temporarily suspended as tourists take advantage of the relative anonymity and freedom from community scrutiny.' Indeed, the notion of tourism occurring in liminoid space melds well with more recent academic literature that holds tourism is a furtive ground for extraordinary experiences (see Morgan et al. 2010; Tung \& Ritchie, 2011). These two-fold discourses, of escape and, in turn, extraordinary experience, attempt to map out tourism space as fundamentally different from the everyday, effectively dichotomising 'home' and 'away'.

In accordance with this modernist position, a postmodernist approach also draws into question the degree to which performances of identity, and hence behaviour, are likely to 
consistently transcend contexts. A performance perspective (Bell, 2008; Edensor, 2001), rising out of Goffman's (1959) work on selves, in which individuals perform different 'faces' depending on the situation, suggests that personal identities are too fragmented, contextuallydependent and relational (Finnegan, 1997; Vaughan and Hogg, 2002) to expect behavioural consistency (for a more exhaustive review of self-identities as multiple and fluid see Cohen, 2010b). Within this perspective, dissonance between attitudes and behaviours and inconsistencies in patterns of behaviour across contexts are each easily reconciled because consistency is not presumed from the start. These modernist and postmodernist worldviews, with behaviour dichotomised between 'here' and 'there' in the former, and performances of identity fragmented and unstable across contexts in the latter, may seem of distant relation when returning to the focus of consumer climate concern and the prospect of sustainable tourism. However, these issues are paramount if seeking to mitigate tourism's climate change impacts through strategies that attempt to nudge tourists towards pro-environmental behaviour. With identities, and in turn, attitudes and behaviours, largely contingent on social context, there can be no certain expectation that consumer climate concern in daily life practices will necessarily transfer across to tourism practices.

\section{Method}

The empirical material presented in this chapter is part of a wider study on consumer climate concern and tourist practices in European markets. The qualitative materials consist of 30 semi-structured open-ended interviews conducted in Norway and the UK in 2009. Our interest in Norway and the UK arises from tensions between the conspicuous aeromobility of sections of their respective populations and government initiatives aimed at mitigating climate change (Gössling, 2009; Hares et al, 2010; Høyer, 2000). The interview programme sought to explore consumer opinions on climate change and engage participants in a discussion of potential climate change concerns and actual behaviours as they relate to both day-to-day domestic and tourism practices.

Interviews were carried out first in Stavanger, Norway (15 participants) and immediately after in Bournemouth, UK (15 participants), when the lead author was based as a visiting researcher at both the University of Stavanger and Bournemouth University. Participants in both locations were recruited using a snowball sampling technique relying initially on key informants in each location, both from within and outside the universities. 
The only selection criteria were participants self-identify as Norwegian or British nationals, respectively, and be willing to be interviewed face-to-face in English. The interview participants included 15 females and 15 males with ages that ranged from 18 to 67 (Table 1). Their occupations reflected 12 industry professionals, six university academics, five university administrators, four postgraduate students, two undergraduate students and one retiree.

Table 1 Summary profile of interview programme participants

\begin{tabular}{|c|c|c|c|c|c|}
\hline Pseudonym & Gender & Age & Nationality & Occupation & Highest qualification \\
\hline Frode & $\mathrm{M}$ & 37 & Norwegian & Industry professional & Masters \\
\hline Rita & $\mathrm{F}$ & 34 & Norwegian & Industry professional & Masters \\
\hline Bjørn & M & 41 & Norwegian & Industry professional & $\mathrm{PhD}$ \\
\hline Silje & $\mathrm{F}$ & 45 & Norwegian & Industry professional & Masters \\
\hline Svein & M & 35 & Norwegian & Industry professional & High school \\
\hline Tone & $\mathrm{F}$ & 58 & Norwegian & Postgraduate student & Masters \\
\hline Ida & $\mathrm{F}$ & 52 & Norwegian & University administrator & Masters \\
\hline Grete & $\mathrm{F}$ & 27 & Norwegian & Postgraduate student & Undergraduate \\
\hline Lars & M & 53 & Norwegian & Academic & $\mathrm{PhD}$ \\
\hline Pål & M & 34 & Norwegian & Industry professional & Masters \\
\hline Hilda & $\mathrm{F}$ & 67 & Norwegian & Retiree & Masters \\
\hline Håkon & M & 48 & Norwegian & Industry professional & Undergraduate \\
\hline Johannes & M & 57 & Norwegian & Academic & $\mathrm{PhD}$ \\
\hline Anette & $\mathrm{F}$ & 35 & Norwegian & Industry professional & Masters \\
\hline Grethe & $\mathrm{F}$ & 27 & Norwegian & Postgraduate student & Masters \\
\hline Cindy & $\mathrm{F}$ & 42 & British & University administrator & High school \\
\hline Jack & M & 35 & British & Industry professional & Undergraduate \\
\hline Grace & $\mathrm{F}$ & 36 & British & University administrator & Masters \\
\hline Jessica & $\mathrm{F}$ & 48 & British & University administrator & High school \\
\hline Ruby & $\mathrm{F}$ & 41 & British & Industry professional & High school \\
\hline Amy & $\mathrm{F}$ & 30 & British & Academic & $\mathrm{PhD}$ \\
\hline Hannah & $\mathrm{F}$ & 48 & British & Postgraduate student & Masters \\
\hline Oliver & M & 30 & British & Academic & Masters \\
\hline Thomas & M & 38 & British & Academic & Masters \\
\hline Harry & M & 40 & British & Industry professional & Undergraduate \\
\hline Daniel & M & 18 & British & Undergraduate student & High school \\
\hline Mia & $\mathrm{F}$ & 21 & British & Undergraduate student & High school \\
\hline James & M & 63 & British & Academic & $\mathrm{PhD}$ \\
\hline William & M & 42 & British & Industry professional & Undergraduate \\
\hline Lewis & M & 39 & British & Industry professional & Undergraduate \\
\hline
\end{tabular}

The majority of the participants were highly educated and moderately affluent, representing the research sample being driven out of a university context, but also reflecting a particularly relevant group to consider when addressing the conspicuous consumption of tourism. It is this sub-set of the total population in Europe who have the economic resources that give them the option of consuming tourist products on a frequent basis. The findings do 
confirm the participants were highly aeromobile for tourism purposes, with several flights per year not uncommon. Participants in both countries expressed a common need for regular holidays in warm destinations outside of their country of origin.

\section{Consistencies between home and away}

The study found significant inconsistencies in the participants' climate sensitivities and related behaviours between domestic day-to-day and tourism contexts. However, a minority of the participants suggested there was no difference between the environmental sustainability of their practices in domestic decisions versus those made whilst away on holiday. As Oliver (British, 30) maintained:

Exactly the same principles would apply. If I'm staying in a hotel, I wouldn't dream of leaving the room with the lights on, for example. If I'm in a hotel, I'm not going to boil more water than I need. I'm not going to stand under the shower for ten minutes longer than is necessary.

This type of statement was typically used to discount the notion that economic motives underpinned some pro-environmental behaviour. William (British, 42) put this issue in a stark light - 'When we go to Florida, I wouldn't just leave the air-conditioning on all day and all night because I'm not paying for it. I would be responsible about it.'

Furthermore, Svein (Norwegian, 35), when asked how important money was in his attitudes towards the environment whilst on holiday, replied:

For me, economics is not a big issue. I'm not above average in Norway. We're so rich and comfortable here and what I want more of in my life is other qualities than monies and luxury and that kind of wealth. So it's not motivated by money.

Svein gave primacy to consuming ethically across the different facets of his life. As he recognizes, however, this is a position of privilege made available through his citizenship in an affluent nation.

In each of these cases, tourism practices were viewed holistically as part of a broader lifestyle in which consistency was sought in values, attitudes and behaviours across different facets of life. Barr et al (2010, p475) describe this notion of a 'sustainable lifestyle' as 
implying 'individuals would demonstrate a series of commitments across lifestyle practices, not merely as part of their routine, but also in tourism contexts'. Svein further elaborated a view that the everyday and holidays as inextricably interlinked, with the carbon savings accumulated through practices such as cycling to work seen as nonsensical when positioned alongside the prospect of flippant tourist air travel: 'So you can't ride your bike to your job and use a plane everywhere without thinking about it - it would be stupid.' This type of consistent 'rational actor' approach, however, was relatively rare in the participants.

\section{Inconsistencies between home and away}

Instead of achieving alignment between approaches to environmental sustainability in everyday practices and those whilst on holiday, participants evidenced that tourism spaces are often the stage for performances of less stringent climate concern and more environmentally destructive consumption practices. Supporting the work of Barr et al (2010), these individuals, who may be committed to environmental practices at home (e.g. reducing waste and energy use, buying organic, 'ethical' purchasing), are often unwilling to reduce holiday air travel. For instance, Harry (British, 40), whose undergraduate degree was in environmental management, undertook a range of practices in everyday life to mitigate his climate impact, but was unwilling to transfer sustainable practices to the realm of tourismrelated air travel, where he privileged speed and convenience over sustainability:

I have a small car with a small engine and that is purely from a global warming point of view, from a pollution point of view. I do see the impact [of air travel] and I would get on an airplane and go on a long-haul flight because I want to travel, I want to get to this place, and I can't think of another way to do it reasonably quickly, reasonably safely, minimum of fuss. It's the convenience, it boils down to that.

Supporting this type of behavioural inconsistency between home and away, Frode (Norwegian, 37) took great interest in reducing waste in his everyday life, but chose not to buy voluntary carbon offsets or reduce his frequent air travel:

I'm not buying $\mathrm{CO}_{2}$ quota on the planes when I'm flying, I'm not buying that. What I'm doing - I'm recycling quite a bit. I think that's the most important thing that I'm doing - I'm quite concerned about how I distribute my garbage. So good with garbage, not that good with travel - travel like always. 
Frode's concern about garbage, but not air travel, may reflect the deep social embeddedness of environmental practices such as recycling within his society, which may have become habit. Quite oppositely, Randles and Mander (2009b) argue that tourist air travel itself has become habit, for some sections of society, and that there are only 'flickerings' of evidence of consumer environmental concern over aviation. Bjørn (Norwegian, 41), however, argued that decisions, rather than being habit, are often consciously weighed, but typically cannot be attributed to a singular motivation, such as climate concern. In his case, as a father, climate concern needed to be balanced against a range of other considerations, such as cost, time and comfort:

These values are a little bit related to how much does it cost for me also, I must admit. I feel like a bit schizophrenic in terms of climate, because on one end I want to contribute and at the same time I have all these requirements during every day with small kids, going to shopping, all this practical stuff you have to do. There is a set of motivating factors, and environmental is one aspect of many. And the importance of that aspect is partly related your situation in life at the present moment.

Bjørn's words suggest that the primacy given to environmental values may vary through the lifecourse, as other demands, such as family, compete in consumption decisions. He also reminds us that motivations are often multidimensional and contextual (Ryan, 1997). Contexts become infused with meaning, and it is the meanings individuals attribute to, and derive from, certain spaces and places that structure behaviour.

\section{Liminoid tourism spaces}

Several of the participants perceived tourism practices as existing relatively outside of the social norms that they used to structure their behaviour in everyday life. In this sense, tourism space was seen as liminoid (Kim \& Jamal, 2007), and hence freer from the behavioural norms and values of the day-to-day. As such, Pål, (Norwegian, 34), when asked if he saw a difference in energy consumption decisions he might take in daily life versus on a holiday, responded:

I think so - because when you're on holiday you're in a different mode. You are somewhere else and you want to get the most out of it and go home and be filled with impressions and experiences. 
Pål viewed the spaces of tourism as extraordinary, wherein climate change sensitivity took backseat to securing memorable experiences, theoretically on offer through tourist practices (Morgan et al, 2010; Tung \& Ritchie, 2011). As Ida (Norwegian, 52) said of making the most of her holidays, rather than stopping to take time to consider their climate impacts - 'I'm not stopping and thinking, no. I'm there and I want to see much and do what I want to do.' Participants who attached too high of an importance to their holidays to consider adapting them because of climate change mirrored the findings of Hares et al (2010), in which there is reluctance to forgo the perceived positive benefits made accessible by tourist air travel in order to reduce personal emissions.

For Rita (Norwegian, 34), both the importance of escaping to an attractive overseas destination to relax and the trip's corresponding economic cost outweighed concern over the climate impacts of her holidays. She attributed this to the relative infrequency of her holidaying:

Holiday trips are maybe once a year and other issues would be more important where to go and economic questions - would be more important on my annual travels. The things I can do every day are easier to be conscious about and to make a decision about then what you do once a year. Because then it's more important to me to go to a nice place and relax for two weeks.

This issue of the difference in frequency between tourism and domestic decisions was also cited as an important factor by Tone (Norwegian, 58):

Daily life is more important. I'm more concerned about daily life because we don't travel all the time. It's [flying] kind of abstract, because you are not doing this every day and it is a little bit away from you when you have landed and then you go home.

Hence, the infrequency of tourism practices, combined with their typical occurrence in spaces outside of everyday life, provided justification for sustainable practices to be temporarily suspended. A temporary suspension of environmental norms when on holidays lends support to Barr et al's (2010, p475) observation that a sustainable lifestyle will only exist once 'individuals are able to transfer their behaviours between contexts, as part of an embedded set of lifestyle practices'. 


\section{Contextualised performances of consumer concern}

Rather than consistent performances of identity aligned with an embedded set of lifestyle practices, through a commitment to reducing climate impacts across all life contexts, many of the participants narrated performances of consumer concern that were contingent upon context. In some cases, the contradiction between striving for sustainable practices in everyday life, only for a single long-haul flight taken to exceed annual per capita sustainable emission levels (Gössling et al, 2009), was duly acknowledged:

I think it's a contradiction. I think a lot of people do it. But you kind of, you kind of try to put it back of your mind and try not to worry about it. Well, you think, I'm seeing the world and it's great for the kids to see the world. So you try to put it to one side. Silly really. (Ruby, British, 41)

In another instance, a participant who regularly stayed in the UK and went camping for her holidays, both because of lower costs and pro-environmental attitudes, recognized that if her economic circumstances were to change, that she would probably not be able to resist taking tourism trips via long-haul air travel - 'Say I won a load of money tomorrow - I'd probably go [to New Zealand]. It's awful, isn't it? You feel guilty but you justify it to yourself in some respect' (Grace, British, 36). Thus, for Grace, her travel behaviour was contingent on the social and economic context in which she might be positioned, rather than an enduring set of core values.

For another participant, different performances were offered between home and away, which while inconsistent, were not recognised as conflictive with the participants' environmental values:

I probably don't think about it actually. You know what, I went to Turkey last year, and it was 40 degrees and we had air conditioning and we left it on. We went out and left the air conditioning on. And I don't think that I, for one moment, thought about the effects on the environment. And I've even done an environmental degree. (Harry, British, 40)

For Harry, who closely monitored his domestic energy consumption at home and even studied for an environmental degree at university, both air travel and energy usage once in the destination were subject to a lower level of climate concern than in daily life practices. 
The inconsistency between these different 'faces' offered depending on context, which constitute what we term 'multiple environmental identities', were not experienced by the participants as a source of concern that needed any mediation or reconciliation. Multiple identities, with climate change sensitivities adapted to suit the participant's needs in each situation, were narrated to make sense of and justify what may be externally perceived as behavioural contradictions. As Lewis (British, 39) revealed of his recent holiday in Florida, after attesting to a grave personal concern about climate change and its potential implications in the future for his two young children:

For example, we've been to Florida, there were four families with four cars and we drove everywhere every single day to a different a location to do something. And even when you're in those locations chances are you're using amenities that are extremely wasteful on electricity and emissions as well. So you think a lot less about the environmental impacts then. You're in an apartment, you pay for it, it's not yours, whether you go out and leave the lights on - chances are you're a lot less environmentally aware when you're on holiday than when you're not.

Indeed, these contradictions in climate concern and environmental behaviour across contexts of home and away serve to further destabilise the notion of sustainable lifestyles.

\section{Conclusion}

This chapter has sought to further understandings of how tourism consumption, a source of significant $\mathrm{CO}_{2}$ contributions, is made sense of and justified by consumers in relation to everyday life decisions. Based on empirical evidence from an aeromobile sub-section of Norwegian and British society, respectively, exploratory findings suggest it is not uncommon for tourism spaces to be subject to lower levels of environmental concern than day-to-day contexts. For our participants, whilst there were some consistencies between the environmental sustainability of their practices in domestic decisions and those made whilst away on holiday, there were also many cases in which their environmentally destructive tourism consumption practices were subject to less stringent, or even exempt from, climate concern.

Whether these behavioural inconsistencies and contradictions are taken as a modern expression of tourism practices occurring in liminoid space, or from a postmodern 
perspective in which identities have become fragmented and contextually-dependent, and hence multiple (Finnegan, 1997; Vaughan and Hogg, 2002), has little bearing upon the phenomena's practical management implications. The outcome of both ways of looking at these contradictions in practice between 'home' and 'away' is that behavioural adaptations motivated by environmental concern do not necessarily, and often do not, transfer across contexts, especially in the case of tourism practices. These findings highlight a significant challenge for both the governance of climate change and agendas for sustainable development. Consequently, strategies that seek to tackle these issues, whether through education or media, by aiming to nudge individual lifestyles towards less carbon-intensive consumption choices, need to be tempered with an awareness that environmental identities, like other aspects of personal identities, cannot be relied upon to lead to consistent behaviour. This indicates that national and international agencies that seek carbon mitigation and sustainable development through even a partial reliance on individual behavioural adaptations, alongside collective political and technological innovations, must recognise the barriers and limits to achieving consistent sustainable lifestyles.

\section{References}

Barr, S., Shaw, G., Coles, T., and Prillwitz, J. (2010) "'A holiday is a holiday": Practicing sustainability, home and away', Journal of Transport Geography, vol 18, no 3, pp474-481

Becken, S. (2007) 'Tourists' perception of international air travel's impact on the global climate and potential climate change policies', Journal of Sustainable Tourism, vol 15 , no 4, pp351-368

Bell, E. (2008) Theories of Performance, Sage, Los Angeles

Burns, P., and Bibbings, L. (2009) 'The end of tourism? Climate change and societal challenges', 21 st Century Society, vol 4, no 1, pp31-51

Caletrío, J. (2011) 'Simple living and tourism in times of 'austerity', Current Issues in Tourism, doi: 10.1080/13683500.2011.556246

Cohen, S.A. (2010a) 'Searching for escape, authenticity and identity: Experiences of 'lifestyle travellers', in M. Morgan, P. Lugosi and J.R.B. Ritchie (eds) The Tourism and Leisure Experience: Consumer and Managerial Perspectives, Channel View, Bristol

Cohen, S.A. (2010b) 'Chasing a myth? Searching for 'self' through lifestyle travel', Tourist Studies, vol 10, no 2, pp117-133

Cohen, S. A., and Higham, J. E. S. (2011) 'Eyes wide shut? UK consumer perceptions on aviation climate impacts and travel decisions to New Zealand', Current Issues in Tourism, vol 14, no 4, pp323-335

Cohen, S.A., Higham, J.E.S. and Cavaliere, C.T. (2011) 'Binge flying: Behavioural addiction and climate change', Annals of Tourism Research, vol 38, no 3, pp1070-1089 
Cohen, S. and Taylor, L. (1992) Escape Attempts: The Theory and Practice of Resistance to Everyday Life, Routledge, London

Crompton, J. (1979) 'Motivations for pleasure vacation', Annals of Tourism Research, vol 6, no 4, pp408-424

Dann, G. (1977) 'Anomie, ego-enhancement and tourism' Annals of Tourism Research, vol 4, no 4, 184-194

De Freitas, C. (2005) 'The climate-tourism relationship and its relevance to climate change impact assessment', in C.M. Hall and J.E.S. Higham (eds) Tourism, Recreation and Climate Change, Channel View, Clevedon

Dickinson, J.E., Lumsdon, L.M. and Robbins, D. (2011) 'Slow travel: Issues for tourism and climate change', Journal of Sustainable Tourism, vol 19, no 3, pp281-300

Edensor, T. (2001) 'Performing tourism, staging tourism', Tourist Studies, vol 1, no 1, pp5981

Edensor, T. (2007) 'Mundane mobilities, performances and spaces of tourism', Social \& Cultural Geography, vol 8, no 2, pp199-215

Finnegan, R. (1997) “'Storying the self”: Personal narratives and identity', in H. Mackay (ed) Consumption and Everyday Life, Sage, London

Goffman, E. (1959) The Presentation of self in everyday life, Penguin Books, Middlesex

Gössling, S. (2009) 'Carbon neutral destinations: A conceptual analysis', Journal of Sustainable Tourism, vol 17, no 1, pp17-37

Gössling, S., and Peeters, P. (2007) '"It does not harm the environment!" An analysis of industry discourses on tourism, air travel and the environment', Journal of Sustainable Tourism, vol 15, no 4, pp402-417

Gössling, S., and Upham, P. (2009) Climate change and aviation: Issues, challenges and solutions, Earthscan, London

Gössling, S., Bredberg, M., Randow, A., Sandström, E., and Svensson, P. (2006) 'Tourist perceptions of climate change: a study of international tourists in Zanzibar', Current Issues in Tourism, vol 9, nos 4\&5, pp 419-435

Gössling, S., Haglund, L., Kallgren, H., Revahl, M., \& Hultman, J. (2009) 'Swedish air travellers and voluntary carbon offsets: Towards the co-creation of environmental value', Current Issues in Tourism, vol 12, no 1, pp1-19

Gössling, S., Peeters, P., and Scott, D. (2008) 'Consequences of climate policy for international tourist arrivals in developing countries', Third World Quarterly, vol 29, no 5, pp873-901

Hares, A., Dickinson, J., and Wilkes, K. (2010) 'Climate change and the air travel decisions of UK tourists', Journal of Transport Geography, vol 18, no 3, pp466-473

Higham, J.E.S. and Cohen, S.A. (2011) 'Canary in the coalmine: Norwegian attitudes towards climate change and extreme long-haul air travel to Aotearoa/New Zealand', Tourism Management, vol 32, no 1, pp98-105

Høyer, K. (2000) 'Sustainable tourism or sustainable mobility? The Norwegian case', Journal of Sustainable Tourism, vol 8, no 2, pp147-160

Kim, H. and Jamal, T. (2007) 'Touristic quest for existential authenticity', Annals of Tourism Research, vol 34, no 1, pp181-201

Lett, J.W. (1983) 'Ludic and liminoid aspects of charter yacht tourism in the Caribbean', Annals of Tourism Research, vol 10, no 1, pp35-56

Miller, G., Rathouse, K., Scarles, C., Holmes, K., and Tribe, J. (2010) 'Public understanding of sustainable tourism', Annals of Tourism Research, vol 37, no 3, pp627-645

Morgan, M., Lugosi, P. and Ritchie, J.R.B. (2010) The tourism and leisure experience: Consumer and managerial perspectives, Channel View, Clevedon 
Peeters, P., and Dubois, G. (2010) 'Tourism travel under climate change mitigation constraints', Journal of Transport Geography, vol 18, no 3, pp447-457

Randles, S., and Mander, S. (2009a) 'Aviation, consumption and the climate change debate: "Are you going to tell me off for flying?", Technology Analysis \& Strategic Management, vol 21, no 1, pp93-113

Randles, S., \& Mander, S. (2009b) 'Practice(s) and ratchet(s): A sociological examination of frequent flying', in S. Gössling \& P. Upham (eds) Climate change and aviation: Issues, challenges and solutions Earthscan, London

Ryan, C. (1997) The Tourist Experience: A New Introduction, Cassell, London

Sharpley, R. (2003) Tourism, Tourists and Society, Elm, Huntingdon

Smith, I. J., and Rodger, C. J. (2009) 'Carbon offsets for aviation-generated emissions due to international travel to and from New Zealand', Energy Policy, vol 37, no 9, pp34383447

Tung, V.W.S. and Ritchie, J.R.B. (2011) 'Exploring the essence of memorable tourism experiences', Annals of Tourism Research, vol 38, no 3, doi: 10.1016/j.annals.2011.03.009

Turner, V. (1982) From Ritual to Theatre: The Human Seriousness of Play, PAJ, New York Vaughan, G. M. and Hogg, M. A. (2002) Introduction to Social Psychology, 3rd edition, Pearson Education, Frenches Forest

Weaver, D. (2011) 'Can sustainable tourism survive climate change?', Journal of Sustainable Tourism, vol 19, no 1, pp5-15 